\title{
Infección por Enterobius Vermicularis \\ y su relación con vulvovaginitis e infección urinaria en niñas
}

\author{
Drs. B. Gottlieb, ${ }^{1}$ M.l. Sims., ${ }^{2}$ C. Saieh, ${ }^{3}$ H. Reyes ${ }^{1}$ y H. Pugas
}

\begin{abstract}
35 girls (from 1 to 14 years of age) with oryurianis were atudied to delermine frecuency of ansocintion with rulrovaginitis and urinary infection.

Patientis were studied through the following achedule: symptoms inquiry; grnecolocical examination; becteriolopical, micological and parasilological studies of the vaginal dischare; urinalyais and urine culture.

Symptoms of vulvovaginitis were detected in $57 \%$ of the eirle and the gynecolagical examination indicated then $91 \%$ had alterations in association with those symptoms, mainly red introito and leucorren.

In only $\mathbf{4 3 \%}$ of the cases it was possible to verify the preacence of an additional infection agent in the vaginal diucharge. In the remaining $57 \%$ the only likely etiology seets to be oxyuriasis.

Urinary infection was present in only one patient. There were 3 casea of Becondary enuresin that disuppeared after appropriate treatment aginst $E$. vermiculcris.
\end{abstract}

Enterobius vermicularis (Oxyuris vermicularis) es un helminto enteroparásito que se localiza en el intestino grueso, en la región ceco-ascendente, donde se adhiere a la mucosa mediante una expan. sión cefálica peribucal. Para colocar sus huevos, la hembra migra hacia la región perianal donde los deposita. ${ }^{1,2}$ En este proceso, puede desviar su trayecto e invadir el tracto genital femenino, legando inclugo hasta la cavidad peritoneal y causar una variada patología que va desde la vulvovaginitis hasta gramulomas pelvianos. ${ }^{3,4,5,6,7,8,9}$ Se ha postulado que también puede migrar hacia la vía urinaria femenina, siendo capaz de provocar infección urinaria por acarreo mecánico de gérmenes. ${ }^{10}$

En nuestro país este parásito tiene alta frecuencia, en especial en la población infantil, alcanzando cifras promedios de infección que oscilan entre 30-80\%, según la población estudiada. ${ }^{11}, 12,13,14,15,16$. 17. 18, 19, 20, $21 \mathrm{Es}$, sin duda, la helmintiasis más frecuente en la población infantil general de Chile.

1 Unidad de Parasitología, Depto, Salud Pública, Faculad de Medícina Santiago Oriente, Universidad de Chile.

2 Jefe Unidad de Ginecología Infantil y Adolescencia, Hospilal L. Calvo Mackenna.

${ }^{3}$ Unidad de Nefrologia, Hospital L. Calvo Mackenne

4 Jefe Uaidad de Parasitología, Depto. Salud Páblica, Facultad de Medicine Santiago Oriente, Universided de Chile.

5 Jefe Unidad de Nefrologia, Hospilal L. Calvo Mackenna.
El propósito de este trabajo fue investigar la frecuencia y tipo de inflamación genital y de infección urinaria en niñas infectadas por $E$. vermicularis, tratando de establecer correlación entre estos hechos.

\section{MATERIAL Y METODO}

Se estudiaron 35 niñas, entre 1,5 a 14 años de edad, que consultaron a la Policlínica de Pediatría, Hospital Luis Calvo Mackenna, Santiago, por causas diverass, y en quienes el estudio parasitológico para diagnóstico de oxyuriasia por método de Graham $^{22}$ resultó positiøo. De estas niñas, 1 era lactante, 11 prescolares y 23 escolares.

A cada niña se le efectuó una encuegta de síntomas, un examen ginecológico completo con toma de muestra de flujo vaginal, examen citoquímico de orina y urocultivo tomado en condiciones asépticas.

La muestra de flujo vaginal se recolectó introduciendo $5 \mathrm{ml}$. de suero fisiológico estéril dentro de la vagina, a través de una sonda fina conectada a una jeringa estéril procediendo a lavar la cavidad y necoger el líquido en 2 tuhos estériles taponadoe para su análisis bacteriológico, cultiva micológico y examen microscópico directo al frasco para Trichomonas taginalis. ${ }^{23}$ 


\section{RESULTADOS}

La Tabla 1 muestra los principales síntomas pesquigados en las 35 niñas, catalogados en digestivos, ginecológicos, urinarios y de otro tipo.

De los digestivos el más frecuente fue dolor abdominal, que ocurrió en 27 pacientes (77\%), siendo preferentemente periumbilical en $20(57 \%)$, y con menos frecuencia en fosa iliaca derecha 4 (11\%) e hipogastrio en 3 (9\%); en 11 pacientes (31\%) ocurría con una periodicidad de dos veces por semana, en 7
(20\%) a diario y en los 9 restantes no se pudo precisar. Hubo, además, prurito anal en 26 pacientes (74\%), meteorismo en 21 (60\%), anorexia en 17 (49\%) y constipación en $10(29 \%)$.

De los ginecológicos, hubo antecedentes de leucorrea en 20 casos (57\%) y de prurito vulvar en 19 (54\%). La leucorrea fue relatada como de color amarillento en $14(40 \%)$, blanco en $6(17 \%)$, de olor desagradable en $14(40 \%)$. Su cantidad fue descrita como escasa en $7(20 \%)$, regular en otros $7(20 \%)$ y abundante en $6(17 \%)$.

\section{TABLA 1}

Síntomas pesquisados en 35 niñas con Oxyuriasis

Hospital L. Calvo Mackenna, Santiago (1979).

\begin{tabular}{|c|c|c|c|c|c|}
\hline Tipo & $\mathrm{N} .^{\circ}$ & $\%$ & Tipo & $\mathrm{N} .^{\circ}$ & $\%$ \\
\hline DIGESTIVOS & & & URINARIOS & & \\
\hline Dolor abdominal & 27 & 77,1 & Diguria & 14 & 40,0 \\
\hline Prurito anal & 26 & 74,3 & Orina mal olor & 10 & 28,6 \\
\hline Meteorismo & 21 & 60,0 & Enuresis primaria & 4 & 11,4 \\
\hline Anoreria & 17 & 46,6 & Envresis secundaria & 3 & 8,6 \\
\hline \multirow{2}{*}{ Constipación } & 10 & 28,6 & Orinas turbias & 2 & 5,7 \\
\hline & & & Hematuria & 1 & 2,9 \\
\hline Ginecológicos & & & Otros & & \\
\hline Leucorrea & 20 & 57,1 & Irritabilidad & 25 & 71,4 \\
\hline \multirow[t]{2}{*}{ Prurito vulvar } & 19 & 54,3 & Prurito nasal & 23 & 65,7 \\
\hline & & & Insomnio & 7 & 20,0 \\
\hline
\end{tabular}

En las urinaries primó la disuria con 14 casos ( $40 \%$ ), con orinas de mal olor en 10 ( $29 \%$ ), orinas turbias en $2(6 \%)$ y hematuria en $1(3 \%)$. Había enuresis primaria en 4 casos ( $11 \%$ ), de los cuales 1 era diurna y 3 nocturna, y enuresis secundariz en 3 casos (9\%), que cedió luego del tratamiento de la oxyuriasio con pamoato de pirvinio.

Entre los síntomas de otro tipo, los principales fue- ron irritabilidad ( $71 \%$ ), prurito nasal (66\%) e insornnio $(20 \%)$.

Los resultados del examen ginecológico aparecen en la Tabla 2. Sólo fue normal en 3 pacientes ( $9 \%$ ) y en los 32 restantes ( $91 \%$ ) reveló diversas anomalías. Entre éstas, el hallazgo de introito congestivo se constató en 23 casos $(66 \%)$, introito congestivo más leucorrea en $7(20 \%)$ y leucorrea sola en $2(6 \%)$. En

\section{TABLA 2}

Examen ginecológico en 35 niñas con Oxyuriagis

Hospital L. Caḷvo Mackenna, Santiago (1979).

\begin{tabular}{lrrlrr} 
Resultado Global & N. ${ }^{\circ}$ & $\%$ & Tipo de Anormalidad & N. ${ }^{\circ}$ & $\%$ \\
\hline Normal & & & Introito enrojecido & 23 & 65,7 \\
Anormal & 3 & 8,6 & Intr. enroj. y leucorrea & 7 & 20,0 \\
\hline
\end{tabular}


una de estas niñas hubo, además, un caso de sinequia parcial posterior.

El estudio bacteriológico, micológico y parasitológico de la muestra de flujo vaginal tomada a las 35 pacientes (Tabla 3), resultó negativo en 20 (57\%) y positivo en $15(43 \%)$. De los agentes aislados, la mayoría resultó de tipo bacteriano, con 13 casos (37\%), habiendo apenas 2 casos $(5,7 \%)$ de infección por Candida albicans y por Trichomonas vaginalis, respectivamente.

\section{TABLA 3}

Resultados del examen de laboratorio del flujo vaginal en 35 niñas con Oxyuriasis. Hospital L. Calvo Mackenna, Santiago (1979).

\begin{tabular}{|c|c|c|c|c|c|}
\hline Resultado Global & N. ${ }^{\circ}$ & $\%$ & Agentes Comprobados & N. ${ }^{0}$ & $\%$ \\
\hline \multirow{5}{*}{ Negativo } & \multirow{5}{*}{20} & \multirow{5}{*}{57,2} & Con Bacterias & 13 & 37,1 \\
\hline & & & Polimicrobiana & 6 & 17,1 \\
\hline & & & Eschertichic coli & 2 & 5,7 \\
\hline & & & Klebsiella sp. & 2 & 5,7 \\
\hline & & & Streptococcus virtidons & $\mathbf{l}$ & 2,9 \\
\hline \multirow[t]{6}{*}{ Positivo } & \multirow[t]{6}{*}{15} & \multirow[t]{6}{*}{42,8} & Neisseria sp. & $\mathbf{l}$ & 2,9 \\
\hline & & & Haemophilus sp. & 1 & 2,9 \\
\hline & & & Con Hongos & 2 & 5,7 \\
\hline & & & Candida albicans & 2 & 5,7 \\
\hline & & & Con Parásitos & 2 & 5,7 \\
\hline & & & Trichomonas vaginalis & 2 & 5,7 \\
\hline
\end{tabular}

En los agentes bacterianos la mayor parte fue de tipo polimicrobiano en 6 casos (17\%). Se logró identificar Escherichia coli y Klebsiella en 2 casos $(6 \%)$, respectivamente; y Streptococcus viridans, $\mathrm{Nej}$ sseria sp. y Haemophilus en 1 caso, respectivamente. En los agentes micológicos se aisló Candida albicans en 2 casos $(5,7 \%)$. En cuanto a parásitos, se encontraron 2 casos $(5,7 \%)$ de Trichomonas vaginalis.

Cabe destacar que de las 20 pacientes con examen de flujo vaginal negativo, $16(80 \%)$ tenjan signos de vulvovaginitis al examen ginecológico y otras 2 sólo síntomas pesquisados al interrogatorio, pero sin alteración del examen ginecológico, lo que $\mathrm{da}$ un total de 18 pacientes $(90 \%)$ con un cuadro clínico de alteración vulvovaginal (Tabla 4).

Finalmente, de los exámenes de orina $\mathbf{3 4}$ resultaron normales y sólo 1 reveló indicios de albúmina, piuria abundante aislada y en placas y el urocultivo positivo a Escherichia coli 100.000 colonias/ml. Esta paciente tenía, además, síntomas de vulvovaginitis.

\section{DISCUSION}

La migración de la hembra de $E$. vermicularis desde la cavidad séptica del intestimo grueso hacia los márgenes externos del ano, para ir a depositar

\section{TABLA 4}

Frecuencia de vulvovaginitis en 20 niñas con Oxyuriasis y examen de laboratorio negativo del flujo vaginal. Hosp. L. Calvo Mackenna, Stgo. (1979)

\begin{tabular}{crrr}
\hline $\begin{array}{c}\text { Vulvovaginitis } \\
\text { Sintomas/Signos }\end{array}$ & N. & $\%$ \\
+ & + & 11 & 55,0 \\
- & + & 5 & 25,0 \\
+ & - & 2 & 10,0 \\
- & - & 2 & 10,0 \\
\hline
\end{tabular}

sus huevos, es un fenómeno normal en el ciclo evolutivo de este parásito. Como al salir al exterior, la hembra puede abarcar un amplio radio de digpersión en torno al orificio anal, alrededor de $6 \mathrm{~cm}, 2$ es fácil que algunas lleguen hasta los genitales femeninos y se deslicen hacia su interior. Pueden aparecer, entonces, lesiones inflamatorias cuyas causas han recibido diversas interpretaciones. Para algusos habría una posible agresión directa del parásito sobre la mucosa del tracto vaginal, ${ }^{1,2,4}$ lo que tal vez sea discutible. Para otros, las causas fundamentales son indirectas y obedecen, por una parte, a un intensa reacción local, a veces granulomatosa, del huésped 
(ya fuertemente sensibilizado por el parasitismo intestinal) frente a la presencia del gusano en una localización ectópica; y por otra, el arrastre de gérmenes y otros microorganismos infecciosos desde el intestino o la piel perineal. ${ }^{\text {, }} 2$ Es dable suponer, también, que en algunos de estos casos actúen varios de estos factores simultánesmente, o que deben considerarse otros, tales como infección genital previa de otra naluraleza, influencia de lesiones traumáticas por rasquido o manjpulación genital, malformaciones, etc.

La penetración profunda del parásito hacia el útero, trompas e incluso cavidad peritoneal parece ser poco frecuente, aunque ha sido comunicada en reiteradas ocasiones. $5,6,7,8,9$ Probablemente esto se debe más bien a lo interesante y espectacular de algunos de estos casos, o a que, en ellos, es posible establecer una correlación directa entre la presencia del parásito y la lesión. Por el contrario, la invasión de los genitales externos y la vagina ha merecido menos atención, pese a ser constatada con relativa mayor frecuencia en la clínica pediátrica habitual. En todo caso, es una complicación de la enterobiasis de manejo mucho mâs simple.

Los síntomas pesquisados en las pacientes estudiadas en esta oportunidad, en una alta proporción son atribuibles a la enterobiasig, en especial los catalogados como digestivos y otras (Tabla 1). Entre éstos destacan el dolor abdominal (77\%), prurito anal (74\%), irritabilidad secundaria (71\%), prucito nasal $(66 \%)$, meteorismo $(60 \%)$, lo que concuerda con otros estudios. 2. 13,24 Estos síntomas se deben a la sensibilidad del huésped frente al parásito. Incluso el dolor abdominal y el meteorismo obedecen más posiblemente a este factor que a una acción mecánica directa sobre la mucosa del intestino grueso.

Es muy llamativa la alta frecuencia de vulvovoginjtis en estas 35 niñas con oxyuriagis, constatada tanto por examen ginecológico $(91 \%$ ) como por la pesquisa de síntomas (57\%), como aparece en Tablas 1 y 2. Esto es del todo inusual en una población pediátrica que se suponia presuntamente sana desde el punto de vista ginecológico o, al menos, que no había acudido por esa causa precisa al hospital. Entre los signos comprobados al examen ginecológico destacan la presencia de introito enrojecido y la leucorrea. El primero apareció como signo exclusivo en el $66 \%$ de los casos y asociado a leucorrea en otro $20 \%$, dando un total de $86 \%$ para este signo (Tabla 2); la leucorrea apareció como signo exclusivo en el $6 \%$ y asociada a introito rojo en otro $20 \%$, dando un total de 26\%. Por otra parte, los resultados del examen bacteriológjco, micológico y parasitológico de la muestra de flujo vaginal tomada a todas las niñas sólo permitió comprobar algunas especies en el $43 \%$, quedando $57 \%$ en que no se comprobó agente causal en el flujo vaginal, pero que tenían oxyuriasis (Tabla 3). Y entre estas últimas se pudo apreciar que $90 \%$ tenia síntomas o signos de vulvovaginitis (Tabla 4), cuya causa, entonces, probable pudiera ser $E$. vermicularis.

Por el contrario, aunque entre las niñas estudiadas pudo pesquisarse que $40 \%$ tenía antecedentes de disuria o de otros síntomas urinarios, éstos tal vez puedan relacionarse más con la vulvovaginitis que con un problema urológico, dado que en apenss 1 caso $(2,9 \%)$ se comprobó una genuina infección urinaria. Tal vez el único sintoma que pudiese relacionarse con $E$. vermicularis en estas pacientes fueron los 3 casos de enuresis secundaria, ya que esta alteración desapareció luego del tratamiento antioxyurótico.

De acuerdo a lo obtenido en este estudio, se concluye que la vulvovaginitis aparece en alta frecuencia en niñas infectadas por $E$. vermicularis, pudiendo establecerse una correlación probable en el $90 \%$ de los casoe en que no se demostró otra causa etiológica. Los signos principales de esta vulvovaginitis son el introito enrojecido y la leucorrea. Respecto a la hipótesis de una posible correlación entre oxyuriasis e infección urinaria, ${ }^{10}$ por arrastre de gérmenes, no pudo ser comprobada en estos casos.

\section{RESUMEN}

35 niñas (1-14 años de edad) con oxyuriasig fueron estudiadas para determinar la frecuencia de asociación con vulvovapinitis $\mathrm{e}$ infección urinaria. A cada una se le practicó encuesta de síntomas, examen ginecológico, estudio bacteriológico, micológico y parasitológico de flujo vaginal, examen citoquímica de orina y urocultivo.

Se registraron sintomas de vulvovaginitis en $57 \%$ de los casos y el examen ginecológico reveló que $91 \%$ tenía alteraciones atribuibles a dicho cuadro, principalmente introito rojo y leucorrea. En solo el $43 \%$ de Los casos pudo comprobarse algún otro agente infeccioso en el flujo vaginal. En el $57 \%$ restante, la única etiología probable parece ser la oxyuriasis.

En solo $l$ caso pudo demostrarge infección urinaria. Hubo 3 casos de enuresis secundaria que desapareció después del tratamiento contra $E$. vermicularis.

\section{REFERENCIAS}

\footnotetext{
${ }^{1}$ Faust, E.C.; Russell, P.F,; Jung, R.C.; Craig-Faust. Paranitokgía Clínica, Selłat Ed., Mexico. 1974.

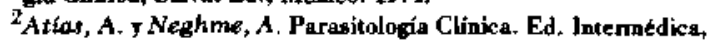
Bs. As.. Argentina. 1979.

${ }^{3}$ Doby.J.M.; Checrel, M.L.; Rault, B. Oxyurave dee voies genitales chez la femme. Arn. Parait. Hum. comp., 36 (1-2): 92-106, 1961 .

${ }^{4}$ Warren, K.S.; Mahmoud, A.F. Algorithms in the Chiogmosis and Management of exotic diseases: Enterobiatis. J. Infec. Dis., 132 (2): 229-232. 1975.
} 
${ }^{5}$ Brooks, T.J.; Goetz, C.C., Plauche, W.C. Pelvic granuloma dne 10 Enterobizs vernicularis. J.A.M.A., 179(7): 492-494, 1962.

'Saffos, R.O.; Rhatigan, R.M. Unilateral Salpingitig due to Enterobitss vermicularis. Amer. J. Clin. Pethol., 67(1): 296-299, 1977

'Chandrasoma, P.T.; Sendts, K.N. Enterobius cermicularis in ectopic sites. Amer. J. Trop. Med, Hyg. 26(4); 644-649. 1977.

${ }^{8}$ Lansmon, H.H.; Laptn, A.; Blaustein, A. Polvic axyurí granuloms associated with endometrioais. Am. J. Obst. Gynec., 76 (6): 1178-1180. 1960.

${ }^{9}$ Campbell, C.G.; Bouman, J. Enterobius vermicularis gramuloma of pelvis. Am. J. Obst. Gypec., 81(2): 256-258, 1961.

${ }^{10}$ Welch, T.R. Pinworm infeatation and urinary tract infection in young girls. Amer. J. Div. Child, 128: 687-898, 1974.

11 Neghme, A.; Siloa, R.; Sotomayor, R. Enteroparaitosis entre escolares de la provincia de Sanniago. Bol. Chil. Parasil., 9: 7075. 1954.

${ }^{12}$ Neghme, A.; Silva, f. Distribución y frecuencia de las onteroparasitosis en Chile. Rev. Serv. Nac. Sulud, 1: 3-24, 1965.

${ }^{13}$ Meneses, C. Contribnción al estudio clínico-epidemialógico de ba Oxyurinsin en Chile. Tesis Med. Ciruj. U. de Chile, I: 465-478, 1952.

${ }^{14}$ Cuevas, R. y col. Frecuencia de infección por Enterobius vermicularis en un internedo. Bol. Chileno Parasit., 24: 121-L23, 1969.

${ }^{15}$ Pamfrez, A y col. Frecuencie en Chile de las infectiones por protozo0 y helmintoe intestinales (1962-1972). B0L Chileno Parasit., 27: 116-118, 1972 .
${ }^{16}$ Atias, A.; Garcia, J. y Leyton, O. Eatudio de la oryurinais an un grupo de alumnos do un inlernado. Bol. Hosp. San Junn de Dios, 20: 103-105, 1973.

${ }^{17}$ Torres, P. y col. Prolozoos y heimintos inteotioales en la población escolar de la ciudad de Valdivia, Chile. Bol Chil. Parasit., 29: 112, 114, 1974.

${ }^{18}$ Sagua H. y Poblete H. Pesquisa de infección por Enterobius vermicularis en nifioes de dos intemados de la ciudad de Antofagasta. Comparación del método de Graham clásico con una modificación del minmo. Bol. Chile. Parssit., 31: 6-7, 1976.

${ }^{19}$ Astorga, B.y Reyes, H. Frecuencia de infeccián por Enterobius vermicularis en la Area de Salud Oriente de Santinpo. Bol. Vig. Enf. Trunem. Zoon., 4 (6): 4-5, 1977.

${ }^{20}$ Schenone, H. y Villarroel, F. Algunos aspectos epidemiolsoicas de las enteroparasitasis en niños de bagares de menores de Sanviago, Chile. Bol. Chileno Paresit, 33; 78-82, 1978.

21 Noemi, 1 . y col. Oxyuriania en la población infantil de la Area de Salud Oriente de Sentiego. Soc. Chilens Paratit., 1978 (inédito).

${ }^{22}$ Grahom, CF. A device for the Dingnonis of Enterobies vermicularis Infection. Amer. J. Trop. Méd., 21 : 159-161, 1941.

${ }^{23}$ Reyes, H. y col. Eatudio nobre Trichomonas vaginalts, hongow y bacterias en muestras de Oujo vepinal. Rev. Méd. Chile, 102: 279-281, 1974.

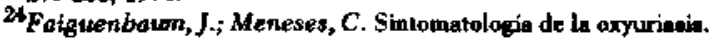
Bol. Chileno Parasit., 9: 10-14, 1954. 